Research Paper

\title{
CA-125, CA-153, and CYFRA21-1 as clinical indicators in male lung cancer with ocular metastasis
}

\author{
Biao Li*, Qing Yuan*, Yu-Ting Zou*, Ting Su, Qi Lin, Yu-Qing Zhang, Wen-Qing Shi, Rong-Bin Liang, \\ Qian-Min Ge, Qiu-Yu Li, Yi Shao ${ }^{\varpi}$ \\ Department of Ophthalmology, The First Affiliated Hospital of Nanchang University, Jiangxi Province Ocular Disease Clinical Research Center, Nanchang \\ 330006, Jiangxi, People's Republic of China \\ *These authors have contributed equally to this work.
}

$\triangle$ Corresponding author: Yi Shao (Email: yxs620@miami.edu, freebee99@163.com; Tel: +086 791-88692520, Fax: +086791-88692520), Department of ophthalmology, The First Affiliated Hospital of Nanchang University, No 17, YongWaiZheng Street, DongHu District, Nanchang 330006, Jiangxi, People's Republic of China; Department of Ophthalmology, Bascom Palmer Eye Institute, University of Miami Miller School of Medicine, Miami, FL, USA

(1) The author(s). This is an open access article distributed under the terms of the Creative Commons Attribution License (https://creativecommons.org/licenses/by/4.0/). See http:/ /ivyspring.com/terms for full terms and conditions.

Received: 2019.05.01; Accepted: 2020.02.08; Published: 2020.02.20

\begin{abstract}
Despite recent improvements in diagnosis and therapy, lung cancer remains the most common malignant tumor in males, with high morbidity and mortality. As the annual incidence continues to increase worldwide, the prognosis for male patients with lung cancer remains unsatisfactory. Interestingly, smoking is associated with lung cancer and ocular lesions by altering risk factors such as carbohydrate antigen (CA)-125, CA-153 and cytokeratin-19 fragment (CYFRA21-1). A diagnostic standard for serum biomarker levels of ocular metastasis (OM) in males with lung cancer is therefore urgently needed. In this retrospective analysis, we examined the relationship between smoking preference and OM in male patients with lung cancer to identify an independent prognostic factor or establish a quantitative indicated standard for OM using the clinical indexes from 2238 cases of male lung cancer. The combination of CA-125, CA-153 and CYFRA21-1 could help diagnose $\mathrm{OM}$ in male lung cancer patients. This finding might lead to more timely diagnosis and effective therapies.
\end{abstract}

Key words: ocular metastasis, lung cancer, men, potential indicators, risk factors, smoking preference

\section{Introduction}

Lung cancer is one of the most malignant tumors in the world, leading to the highest morbidity and mortality among male cancer patients [1]. Patients in low- and middle-income countries now account for more than $50 \%$ of lung cancer deaths annually [1] since they have high smoking rates. LemjabbarAlaoui and colleagues reported that about $\sim 90 \%$ of lung cancer is caused by smoking and tobacco product use [2]. Multiple inherited [3] and acquired mechanisms of susceptibility to lung cancer have also been proposed [2].

Smoking is one of the most significant pathogenic factors of male lung cancer[4,5]. This habit is also associated with eye diseases like hyperopia, delayed corneal epithelial healing, progression of
Fuchs' endothelial corneal dystrophy, age-related nuclear cataract, retinal diseases, uveitis, optic neuropathies, and thyroid-associated orbitopathy [6]. We therefore suspected that smoking might be associated with the occurrence of ocular metastasis $(\mathrm{OM})$ from lung cancer.

Rapid metastasis significantly contributes to the high mortality rates of lung adenocarcinoma [7, 8]. One group described a rare case of primary lung adenocarcinoma with concomitant gastric, duodenal, bone, and mediastinal lymph node metastases, even gastrointestinal metastases [8]. The eye is a rare metastasis site for lung cancer [9] because of vasculature [10] and lymphatics [11]. The incidence of OM from metastatic lung cancer was reported as $6.7 \%$ 
[12]. Traditional computed tomography (CT) and magnetic resonance imaging (MRI) cannot diagnose early stage lung cancer. Accurate diagnosis is needed to guide treatments including surgery, radiation, chemotherapy, and targeted therapies [2].

Namad and colleagues reported a case of bilateral choroidal metastasis from non-small cell lung cancer. A 59-year-old Caucasian female patient was diagnosed with malignant lung cancer, and during follow-up, she presented with bulge on her left eye. Her follow-up chest scan simultaneously showed increases in the size of lung nodules. Her performance status remained stable at that time, except for a mild increase in dyspnea [12]. This case reflects the importance of early diagnosis of metastasis from lung cancer.

Compared with candidate lung cancer biomarkers using molecular diagnostics [13, 14], blood test is a simple diagnostic tool popular throughout China's hospitals. An effective blood test gives prognostic information to help clinicians make case judgements. Serum biomarkers have long been studied to establish a reliable standard to quickly identify metastasis, supplemented with "gold standard" diagnostic methods such as imaging and tissue biopsies.

In our retrospective analysis, we examined individual and composite serum indicators associated with $\mathrm{OM}$ in male lung cancer, and a diagnosis standard was developed.

\section{Materials and Methods}

\section{Study design}

This study was conducted in accordance with the Declaration of Helsinki and approved by the medical research ethics committee of the First Affiliated Hospital of Nanchang University. The methods implemented in this study were conducted under relevant regulations. Therefore, the study results are uncontested by all authors. Serum samples of male patients with lung cancer were preoperatively collected from July 5, 2005 to July 25, 2016. We looked at records from 2238 male lung cancer patients admitted to our hospital. Based on the histopathological examination of samples collected by surgical resection or needle biopsy techniques, patients were categorized into two groups: $\mathrm{OM}$ and non-OM (NOM). The inclusion criteria for the $\mathrm{OM}$ group were non-primary ocular malignant tumor, non-ocular benign tumor, non-hereditary disease, non-distant metastases (apart from the eyes), and non-cardiovascular or non-cerebrovascular disease. OM diagnoses were made using CT or MRI and proved histologically or cytologically. The inclusion criteria for the NOM group were no secondary lung cancers, no organ metastases, and no lymph node metastases. All subjects of the study were fully informed of the purpose of the clinical study, agreed to participate, and signed informed consent forms.

\section{Data collection}

All male patients who had pulmonary carcinoma proved by imaging examination such as CT and MRI were recruited for this study. Diagnoses were confirmed by pulmonary tissue biopsy. The clinical data of this retrospective study including age, histopathology types, and treatments were collected from the records in the medical system. Serum levels of metastatic general serum biomarkers, such as alpha-fetoprotein (AFP), carcinoembryonic antigen (CEA), carbohydrate antigen (CA)-125, CA-199, CA153, CA-724, cytokeratin-19 fragment (CYFRA21-1), total prostate-specific antigen (TPSA), free prostatespecific antigen (FPSA), and neuron-specific enolase (NSE) as well as alkaline phosphatase (ALP), calcium, and hemoglobin $(\mathrm{HB})$ were all recorded at the time of initial diagnosis of lung cancer.

\section{Statistical analyses}

Student's $t$ tests and chi square tests were performed to identify differences between the OM and NOM groups. Then, binary logistic regression models were generated to assess the values of different serum biomarkers for $\mathrm{OM}$ in male lung cancer. Receiver operating characteristic (ROC) curves were plotted, and the areas under the curve (AUCs) were calculated to determine the diagnostic utilities of risk factors. $\mathrm{P}<0.05$ for a two-sided test was considered statistically significant. Statistical analyses were performed with SPSS version 17.0 software (SPSS Inc, Chicago, IL, USA), MedCalc18.6.0 statistical software (MedCalc, Ostend, Belgium) and Excel 2016 software (Microsoft Corp, Redmond, WA, USA). Clinical measurement data are presented as means \pm standard deviations (SD).

\section{Results}

\section{Demographics and clinical characteristics}

A total of 2238 male patients including $50 \mathrm{OM}$ cases (16 orbital metastasis and 34 intraocular metastasis cases) and $2188 \mathrm{NOM}$ cases were recruited for this study. The average ages of the OM and NOM subjects were $58.82 \pm 10.32$ and $61.23 \pm 10.32$ years, respectively $(\mathrm{P}>0.05)$. Smoking preference was significantly different between groups $(\mathrm{P}<0.05)$ which confirmed that smoking is associated with OM in male lung cancer patients and is related to the occurrence of lung adenocarcinoma. We also observed differences histopathology types between 
the two groups $(\mathrm{P}<0.05)$. Squamous cell carcinoma and adenocarcinoma were the most common types in the NOM and OM groups, respectively. From 2005 to 2016, the majority of patients underwent chemotherapy and surgery. Patients' detailed clinical features are listed in Table 1. Table 2 shows the relationship between smoking and histopathology types.

\section{Differences in the clinical features and risk factors for $O M$}

Compared with the NOM group, significantly higher concentrations of AFP, CEA, CA-125, CA-199, CA-153, CYFRA21-1, ALP, and TPSA were measured in the OM group $(\mathrm{P}<0.05)$. The serum levels of CA724, FPSA, NSE, calcium, and HB were not significantly different between the two groups ( $\mathrm{P}>0.05$ ). The results are shown in Table 3 . The binary logistic regression results showed that CA-125, CA-153, and CYFRA21-1 were independent risk factors for OM. The detailed results are listed in Table 4.

Table 1. The clinical characteristics of male patients with lung cancer

\begin{tabular}{|c|c|c|c|}
\hline \multirow[t]{2}{*}{ Characteristics } & \multirow{2}{*}{$\begin{array}{l}\text { OM group } \\
(n=50)\end{array}$} & \multirow{2}{*}{$\begin{array}{l}\text { NOM group } \\
(n=2188)\end{array}$} & \multirow[t]{2}{*}{ P value* } \\
\hline & & & \\
\hline \multicolumn{4}{|l|}{ Age $^{\#}$} \\
\hline Mean & $58.82 \pm 10.32$ & $61.23 \pm 10.32$ & 0.157 \\
\hline \multicolumn{4}{|l|}{ Smoking statue } \\
\hline Ever/Current & $25(50.0 \%)$ & $483(22.1 \%)$ & $<0.001$ \\
\hline Never & $25(50.0 \%)$ & $1705(77.9 \%)$ & \\
\hline \multicolumn{4}{|l|}{ Histopathological type $\mathrm{e}^{\# \#}$} \\
\hline Squamous cell carcinoma & $7(14.0 \%)$ & $970(44.3 \%)$ & $<0.001$ \\
\hline Adenocarcinoma & $34(68.0 \%)$ & $759(34.7 \%)$ & \\
\hline Large cell carcinoma & $0(0.0 \%)$ & $29(1.3 \%)$ & \\
\hline Small cell lung cancer (SCLC) & $5(10.0 \%)$ & $306(14.0 \%)$ & \\
\hline Other NSCLC & $0(0.0 \%)$ & $23(1.1 \%)$ & \\
\hline Unknown & $4(8.0 \%)$ & $101(4.6 \%)$ & \\
\hline \multicolumn{4}{|l|}{ Treatment } \\
\hline Surgery & 7 & 555 & \\
\hline Chemotherapy & 28 & 986 & \\
\hline Radiotherapy & 12 & 130 & \\
\hline Symptomatic treatment & 3 & 403 & \\
\hline Others & 0 & 114 & \\
\hline \multicolumn{4}{|c|}{$\begin{array}{l}\text { Notes: OM group included } 16 \text { orbital metastasis cases and } 34 \text { intraocular metast } \\
\text { cases. \#: Student-t test was used. \#\#: Chi-square test was used. *: comparison } \\
\text { between OM group and NOM group. P }<0.05 \text { represented statistically significan } \\
\text { Abbreviations: OM, ocular metastasis; NOM, non-ocular metastasis; NSCLC, } \\
\text { non-small cell lung cancer. }\end{array}$} \\
\hline
\end{tabular}

Table 2. The histopathological type of male lung cancer with smoking or non-smoking

\begin{tabular}{llll}
\hline Histopathological type & Smoking & Non-smoking & P value $^{*}$ \\
\cline { 2 - 3 } & $\mathbf{( n = 5 0 8 )}$ & $\mathbf{( n = 1 7 3 0 )}$ & \\
\hline Squamous cell carcinoma & $127(25.0 \%)$ & $850(49.1 \%)$ & $<0.001$ \\
Adenocarcinoma & $286(56.3 \%)$ & $507(29.3 \%)$ & \\
Large cell carcinoma & $5(1.0 \%)$ & $24(1.4 \%)$ & \\
Small cell lung cancer (SCLC) & $57(11.2 \%)$ & $254(14.7 \%)$ & \\
Other NSCLC & $6(1.2 \%)$ & $17(1.0 \%)$ & \\
Unknown & $27(5.3 \%)$ & $78(4.5 \%)$ & \\
\hline Notes: \#: Chi-square test was used. *: comparison of all histopathological types \\
between OM group and NOM group. P<0.05 represented statistically significant. \\
Abbreviations: NSCLC, non-small cell lung cancer.
\end{tabular}

Table 3. Differences of tumor markers between male lung cancer patients with and without OM

\begin{tabular}{lllll}
\hline Tumor markers & OM group & NOM group & $\mathbf{t}$ & P value \\
\hline AFP $(\mathbf{n g} / \mathrm{ml})$ & $2.72 \pm 1.47$ & $1.73 \pm 1.55$ & -4.662 & $<0.001$ \\
CEA $(\mathbf{n g} / \mathbf{m l})$ & $207.15 \pm 518.34$ & $38.93 \pm 221.65$ & -5.057 & $<0.001$ \\
CA-125 (U/ml) & $310.24 \pm 504.79$ & $61.23 \pm 157.43$ & -10.060 & $<0.001$ \\
CA-199 (U/ml) & $142.39 \pm 338.01$ & $33.95 \pm 228.20$ & -3.280 & 0.001 \\
CA-153 (U/ml) & $96.86 \pm 127.80$ & $18.64 \pm 27.86$ & -16.306 & $<0.001$ \\
CA-724(U/ml) & $11.43 \pm 32.91$ & $12.97 \pm 46.83$ & -0.347 & 0.737 \\
CYFRA21-1(ng/ml) & $31.94 \pm 23.57$ & $8.72 \pm 27.41$ & -5.940 & $<0.001$ \\
TPSA & $3.85 \pm 2.41$ & $1.63 \pm 4.09$ & -6.254 & $<0.001$ \\
FPSA & $0.31 \pm 0.19$ & $2.30 \pm 26.48$ & 1.121 & 0.264 \\
NSE (pg/L) & $34.20 \pm 33.94$ & $25.99 \pm 40.87$ & -1.667 & 0.101 \\
ALP (U/L) & $116.64 \pm 62.72$ & $91.74 \pm 66.29$ & -2.772 & 0.008 \\
Calcium (mmol/L) & $2.27 \pm 0.22$ & $2.29 \pm 1.70$ & 0.386 & 0.700 \\
HB (g/L) & $115.86 \pm 23.16$ & $120.90 \pm 19.35$ & 1.812 & 0.070 \\
\hline
\end{tabular}

Notes: Independent samples-t test was applied. $\mathrm{P}<0.05$ represented statistically significant. Abbreviations: OM, ocular metastases; NOM, non-ocular metastases; $\mathrm{HB}$, hemoglobin

Table 4. Risk factors of OM in male lung cancer patients

\begin{tabular}{lllll}
\hline Factors & B & $\operatorname{Exp}(\mathbf{B})$ & OR $(\mathbf{9 5} \% \mathbf{C I})$ & $\mathbf{P}$ \\
\hline AFP & 0.149 & 1.161 & $1.032-1.306$ & 0.013 \\
CEA & 0.001 & 1.001 & $1.000-1.001$ & 0.001 \\
CA-125 & 0.002 & 1.002 & $1.002-1.003$ & $<0.001$ \\
CA-153 & 0.015 & 1.015 & $1.011-1.019$ & $<0.001$ \\
CYFRA21-1 & 0.009 & 1.009 & $1.005-1.013$ & $<0.001$ \\
TPSA & 0.037 & 1.038 & $1.012-1.064$ & 0.003 \\
CA-199 & $<0.001$ & 1.000 & $1.000-1.001$ & 0.040 \\
ALP & 0.003 & 1.000 & $1.000-1.005$ & 0.018 \\
\hline Notes: Binary logistic Analysis was applied. P <0.05 represented statistically \\
significant. Abbreviations: B, coefficient of regression; OR, odds ratio; CI, \\
confidence interval; OM, ocular metastases; Exp(B), index of B coefficient; AFP, \\
alpha-fetoprotein; CA, carbohydrate antigen; CYFRA, cytokeratin-19 fragment; \\
TPSA, total prostate-specific antigen.
\end{tabular}

Table 5. The cutoff value, sensitivity, specificity and AUC for single risk factor in predicting $O M$ in male lung cancer patients

\begin{tabular}{llllll}
\hline Factor & $\begin{array}{l}\text { Cut-off } \\
\text { value }\end{array}$ & $\begin{array}{l}\text { Sensitivity } \\
(\mathbf{\%})\end{array}$ & $\begin{array}{l}\text { Specificity } \\
(\mathbf{\%})\end{array}$ & AUC & P \\
\hline CA-125 $(\mathrm{U} / \mathrm{ml})$ & 76.56 & 60.00 & 85.56 & 0.754 & $<0.001$ \\
CA-153 $(\mathrm{U} / \mathrm{ml})$ & 22.33 & 70.00 & 82.76 & 0.790 & $<0.001$ \\
CYFRA21-1(ng/ml) & 10.70 & 72.00 & 87.09 & 0.838 & $<0.001$ \\
CA-125+CA-153 & - & 74.00 & 81.89 & 0.827 & $<0.001$ \\
CA-125+CYFRA21-1 & - & 74.00 & 84.12 & 0.834 & $<0.001$ \\
CA-153+CYFRA21-1 & - & 80.00 & 80.45 & 0.850 & $<0.001$ \\
CA-125+CA-153+CYFRA2 & - & 82.00 & 82.92 & 0.859 & $<0.001$ \\
1-1 & & & & &
\end{tabular}

Notes: Sensitivity and specificity were obtained at the point of cutoff value. $\mathrm{P}<0.05$ represented statistically significant. Abbreviations: AUC, area under the curve; $\mathrm{CI}$, confidence interval; OM, ocular metastasis.

\section{The cut-off values, AUCs, sensitivities, and specificities of CA-125, CA-153, and CYFRA21-1 for diagnosing OM}

Fig. 1 shows the ROC curves for CA-125, CA-153, and CYFRA21-1 as male-specific single risk factors, and Table 5 shows the cut-off values of CA-125, CA-153, and CYFRA21-1 as 76.56 U/ml, 22.33 $\mathrm{U} / \mathrm{ml}$, and $10.70 \mathrm{ng} / \mathrm{ml}$, respectively. The AUC of CYFRA21-1 was the highest among single risk factors. Fig. 2 shows the ROC curves of combinations of serum levels for CA-125 + CA-153, CA-125 + CYFRA21-1, CA-153 + CYFRA21-1, and CA-125 + 
CA-153 + CYFRA21-1. We found that the combination of CA-125 + CA-153 + CYFRA21-1 had the largest AUC, which reached 0.859. Among all potential indicators, the combination of CA-125 + CA-153 + CYFRA21-1 had the highest sensitivity, while CYFRA21-1 had the highest specificity. All the results were statistically significant.

\section{Discussion}

The incidence of lung cancer in males continually increased through the late 90s, although it has slightly declined [15]. Lung cancer is still a serious malignant tumor. The incidence and mortality both seem to increase with age [16], and for people $\geq 65$ it accounts for approximately $50 \%$ of all cancer cases and cancer-caused deaths [15]. Despite extensive research and considerable medical progress, a cure for lung cancer remains elusive.

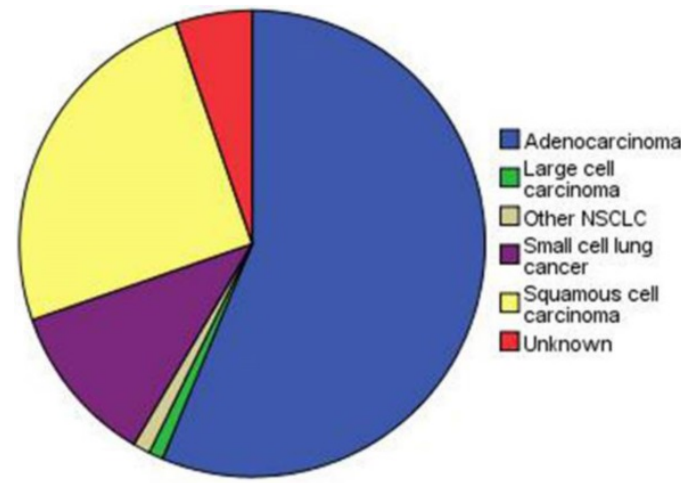

Histopathological types of smoking male patients
The main cause of lung cancer is certainly smoking [17], and it is highly possible that individual lifestyle and nutrition; genetic predisposition; and exposure to asbestos, arsenic, aromatic hydrocarbons, and pollution are also responsible for lung cancer cases [15].

Men who smoke have an increased risk of lung cancer. Numerous clinical investigations for pathological changes show that smoking is inextricably linked to lung disease. Smoking-related lung abnormalities are now an increasing public health concern [18]. According to large-cohort studies, approximately $8 \%$ of smokers have interstitial lung abnormalities [19], and a variety of pathological and physiological abnormalities exist in the lungs of smokers and ex-smokers, including emphysema and various interstitial lung diseases (ILDs). Traditional smoking-related lung diseases include Langerhans

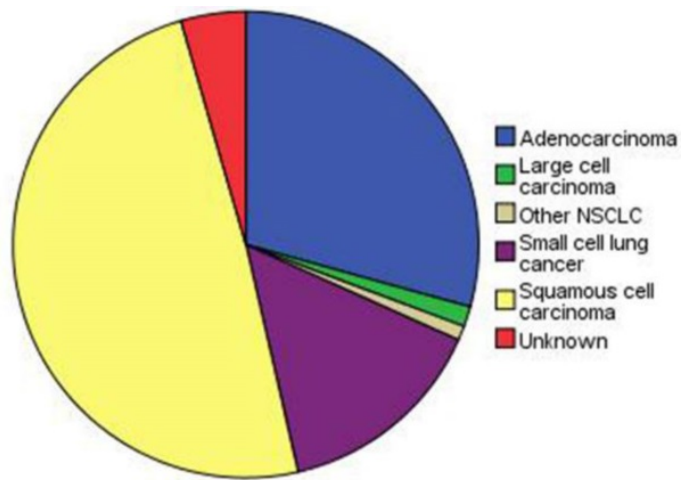

Histopathological types of non-smoking male patients

Figure 1. Histopathological types of smoking and non-smoking patients in male lung cancer.

ROC Curves of Different Factors

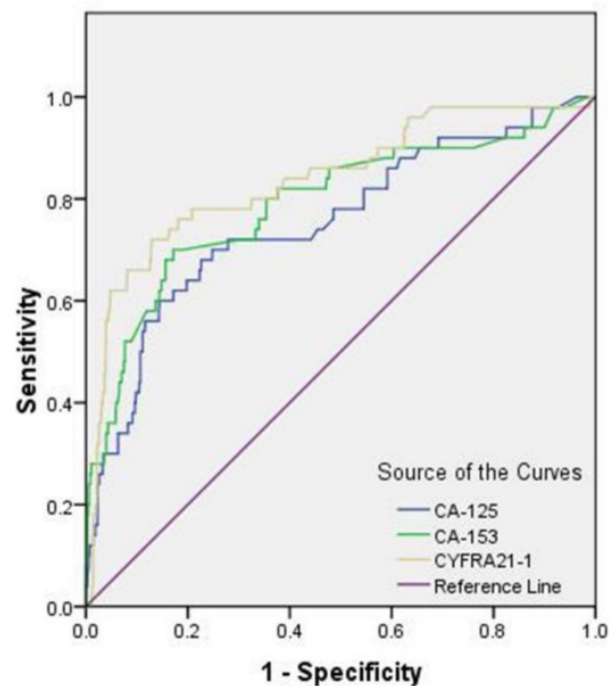

ROC Curves of Combination of Factors

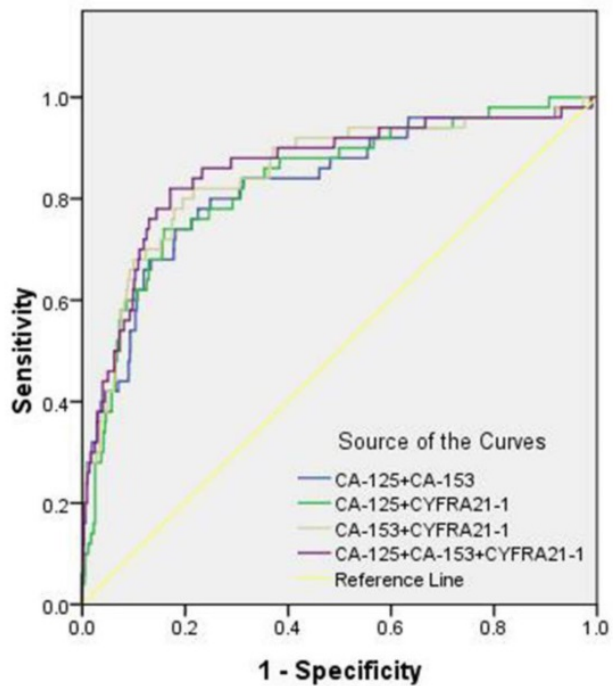

Figure 2. The ROC curves of risk factors for detecting OM in male lung cancer. Notes: (a) ROC curves of CA-125, CA-153 and CYFRA21-1 as single risk factor of OM. (b) ROC curves of combination of CA-125, CA-153 and CYFRA21-1 to detected OM in male lung cancer. Abbreviations: ROC, receiver operating characteristic; OM, ocular metastasis. 
cell histiocytosis (LCH), respiratory bronchiolitis-ILD (RB-ILD), and desquamative interstitial pneumonia (DIP) [20]. Smoking is also a risk factor for chronic fibrosing interstitial pneumonias including usual interstitial pneumonia (UIP) and non-specific interstitial pneumonia (NSIP) [21], as well as unclassifiable idiopathic interstitial pneumonias (unclassifiable IIPs) [22]. These abnormalities are associated with a relatively high risk of all-cause mortality [9], and some progress to pulmonary fibrosis [23]. Finally, tuberculosis and pneumonia can also increase lung cancer risk [24].

At present, there is no worldwide unified diagnostic standard for tobacco dependence [25, 26]. Generally, drug-dependent diagnostic standards including nicotine in the International Classification of Diseases (ICD-10) are used. A person can be considered to have a smoking preference if he has experienced or demonstrated at least 3 of the following 6 items in the past year: 1) strong craving to smoke; 2) difficulty controlling smoking behavior; 3 ) withdrawal symptoms sometimes occur when stopping or reducing the amount of smoking; 4) tobacco tolerance performance, that is, the need to increase the amount of smoking to obtain the experience that could be obtained by smoking less in the past; 5) gave up or reduced other activities and preferences in order to smoke; 6) and continued to smoke regardless of the dangers. According to the quantitative criteria of male smoking preference [Table 6], we classified moderate tobacco dependence and severe tobacco dependence into "Ever/Current" smoking statue, then classified mild tobacco dependence into "Never" smoking statue, finally divided all samples regardless of the presence of $\mathrm{OM}$ into two groups to observe their histopathological type. The smoking group has a higher probability of adenocarcinoma $(56.3 \%)$, while the non-smoking group has a high incidence rate of squamous cell carcinoma $(49.1 \%)$. Table 2 shows that smoking is more likely to cause lung adenocarcinoma. Yao et al. reported that smoking led to downregulation of histone deacetylase- 2 and interleukin- 8 and upregulation of tumor necrosis factor-a in lung adenocarcinoma tissues, and these changes were especially pronounced in smoking combined with chronic obstructive pulmonary disease [17].

Among malignant diseases, lung cancer is the leading cause of morbidity and mortality in China [27]. Approximately $57 \%$ of lung cancer patients have distant metastases at the initial diagnosis, which is associated with poor outcomes [27]. The incidence of OM from lung cancer is reported to be $0.1-7 \%$, with adenocarcinoma and small cell lung cancer accounting for the highest proportions of these cases
[28]. Guo et al. reported an interesting case in which a woman presented with a 1-week history of left eye pain and blurred vision. Examination revealed central lung cancer in the right lower lobe with OM. After surgery and chemotherapy, her eye symptoms disappeared, the ocular lesion was well controlled without any specific ocular treatment, and she achieved prolonged progression-free survival (PFS) [28]. If a quantitative indicator standard of serum risk factors for early diagnosis is established, it can effectively prolong PFS, which is one of the most significant goals of our study. Nanoparticle-based therapeutics are currently paving a new way for the diagnosis, imaging, screening, and treatment of primary and metastatic tumors [29]. Eventually, treatment will be much easier, and the mortality rate will be greatly reduced.

Table 6. Fagerstrm Tobacco Dependence Assessment Scale: Assessing Tobacco Dependence

\begin{tabular}{|c|c|c|c|c|}
\hline Evaluation items & 0 & 1 & 2 & 3 \\
\hline $\begin{array}{l}\text { How long do you take the first cigarette } \\
\text { after waking up in the morning? }\end{array}$ & $\begin{array}{l}>60 \\
\text { minutes }\end{array}$ & $\begin{array}{l}31-60 \\
\text { minutes }\end{array}$ & $\begin{array}{l}6-30 \\
\text { minutes }\end{array}$ & $\leq 5$ minutes \\
\hline $\begin{array}{l}\text { Are you having difficulty controlling } \\
\text { smoking in many non-smoking areas? }\end{array}$ & no & & & yes \\
\hline $\begin{array}{l}\text { Which cigarette do you think you are } \\
\text { most reluctant to give up? }\end{array}$ & $\begin{array}{l}\text { other } \\
\text { time }\end{array}$ & & & $\begin{array}{l}\text { first in the } \\
\text { morning }\end{array}$ \\
\hline $\begin{array}{l}\text { How many cigarettes do you smoke } \\
\text { every day? }\end{array}$ & $\leq 10$ & $11-20$ & $21-30$ & $>30$ \\
\hline $\begin{array}{l}\text { Did you smoke more than the other hour } \\
\text { in the first hour after waking up in the } \\
\text { morning? }\end{array}$ & no & & & yes \\
\hline $\begin{array}{l}\text { Are you still smoking when you are sick } \\
\text { in bed? }\end{array}$ & no & & & yes \\
\hline
\end{tabular}

Our results also identified AFP, CEA, CA-125, CA-153, CYFRA21-1, and TPSA as six clinically available biomarkers for $\mathrm{OM}$ in male lung cancer patients. CA-125, CA-153, and CYFRA21-1 are closely related to OM $(\mathrm{P}<0.05)$. Meanwhile, AFP has been associated with liver cancer [30], and CEA is a broad-spectrum tumor marker used to assess the progression and prognosis of colorectal cancer [31], breast cancer [32], and lung cancer [33]. Its specificity and sensitivity are limited, and CEA only has auxiliary value in diagnosis. Other studies revealed that serum CEA levels have a clear relationship with colorectal cancer stage [34], and TPSA is closely associated with prostate cancer [35].

Finally, we performed binary logistic regression analyses to assess the utility of CA-125, CA-153, and CYFRA21-1 as serum biomarkers for OM in male lung cancer. The highest sensitivity and specificity for a single risk factor were for CYFRA21-1, at $72.00 \%$ and $87.09 \%$, respectively, while the values for the combination of CA-125, CA-153, and CYFRA21-1 were $82.00 \%$ and $82.92 \%$, respectively. The combined 
value for the diagnostic specificity of the three risk factors was greater than any alone. The ROC curves show that the combination of CA-125 + CA-153 + CYFRA21-1 had the highest AUC value (0.859) for the diagnosis of $\mathrm{OM}$ in male lung cancer. Accordingly, it could be a useful combination of biomarkers for early clinical detection of male lung cancer. A reliable, sensible, and convenient clinical standard can be provided using the cut-off values of CA-125 (> 76.56 $\mathrm{U} / \mathrm{ml}), \mathrm{CA}-153$ (> $22.33 \mathrm{U} / \mathrm{ml})$, and CYFRA21-1 (> $10.70 \mathrm{ng} / \mathrm{ml}$ ). A three-biomarker panel (CA-125, CA-153, and CYFRA21-1) could allow classification of lung cancer with or without $\mathrm{OM}$, with excellent sensitivity and specificity.

There are some limitations inherent to our study. First, the sample size of this retrospective analysis is small, especially for the OM group, so it can only be determined that smoking affects these biomarker levels but is not fully identifiable as a key factor. Serum biomarkers were collected and analyzed at the time of diagnosis, not at baseline. The biomarkers developed thus far are not the most ideal due to the limited sensitivity and specificity both individually and as a panel. Finally, all male patients were diagnosed in the same hospital. Further studies are needed in large samples of patients from multiple centers.

Table 7. The risk factors of metastases of male lung cancer

\begin{tabular}{|c|c|c|c|c|}
\hline Author & Year & $\begin{array}{l}\text { Histopathological } \\
\text { type }\end{array}$ & Metastatic sites & Risk factor \\
\hline Lina Wu et al [37] & 2017 & NSCLC & Lymph node & MicroRNA-422a \\
\hline Chu Y et al [38] & 2017 & Adenocarcinoma & Lymph node & $\begin{array}{l}\text { CLSTN1, CLU, } \\
\text { NGAL }\end{array}$ \\
\hline Brody R et al [39] & 2017 & NSCLC & NS & PD-L1 \\
\hline Wu S et al [40] & 2016 & NSCLC & Lymph node & B7-H3 \\
\hline Chen $Y$ et al [41] & 2015 & NSCLC & Brain & NSE \\
\hline Jain L et al [42] & 2009 & NS & NS & SNP \\
\hline Oshiro $Y$ et al[43] & 2004 & Adenocarcinoma & Liver & AFP \\
\hline Nikliński J et al [44] & 1992 & NSCLC & Lymph node & SCC \\
\hline $\begin{array}{l}\text { Hirashima } \mathrm{T} \text { et } \\
\text { al[45] }\end{array}$ & 2000 & NSCLC & NS & telomere \\
\hline Pollán M et al[46] & 2003 & NSCLC & NS & CA-125 \\
\hline Zhou Y et al[47] & 2017 & NS & Bone & CA-125, ALP \\
\hline Cedrés $S$ et al ${ }^{[48]}$ & 2011 & NSCLC & Brain & CEA, CYFRA21-1, \\
\hline Dan Liu et al [49] & 2017 & Adenocarcinoma & $\begin{array}{l}\text { Brain, lymph } \\
\text { node }\end{array}$ & CA-125 \\
\hline Chen F et al[50] & 2015 & NS & Lymph node & CYFRA21-1, CEA \\
\hline Lee DS et al[51] & 2012 & NSCLC & Brain & CEA \\
\hline Morita S et al[52] & 2019 & NSCLC & $\begin{array}{l}\text { Intertrabecular } \\
\text { Vertebral }\end{array}$ & CEA \\
\hline Shetty D et al[53] & 2016 & NSCLC & $\begin{array}{l}\text { Thyroid gland, } \\
\text { lymph node }\end{array}$ & PSMA \\
\hline
\end{tabular}

Abbreviations: NS, not specific; NSCLC, non-small cell lung cancer; SCC, squamous cell carcinoma antigen; CLSTN1, calsyntenin-1; CLU, clusterin; NGAL, neutrophil gelatinase-associated lipocalin; SNP, single nucleotide polymorphisms; PD-L1, programmed cell death-1; B7-H3, B7 homolog 3; PSMA, prostate-specific membrane antigen.

In conclusion, the combination of CA-125 + CA-153 + CYFRA21-1 is of value in the diagnosis of $\mathrm{OM}$ in male lung cancer. If the patient's serum levels are CA-125 > $76.56 \mathrm{U} / \mathrm{ml}, \mathrm{CA}-153>22.33 \mathrm{U} / \mathrm{ml}$, and CYFRA21-1 > $10.70 \mathrm{ng} / \mathrm{ml}, \mathrm{CT}$ or MRI should be performed to check for OM. The combination of CA-125, CA-153, and CYFRA21-1 level is also prognostically valuable. The higher the combined level, the higher probability of OM, which can be a supplementary diagnostic indicator for OM from lung cancer in male patients [36]. And Table 7 shows some risk factors of metastases of male lung cancer in recent years.

\section{Competing Interests}

The authors have declared that no competing interest exists.

\section{References}

1. Torre LA, Siegel RL, Jemal A. Lung Cancer Statistics. Advances in experimental medicine and biology. 2016; 893: 1-19.

2. Lemjabbar-Alaoui H, Hassan OU, Yang YW, Buchanan P. Lung cancer: Biology and treatment options. Biochimica et biophysica acta. 2015; 1856: 189-210

3. Han L, Lee CK, Pang H, Chan HT, Lo IL, Lam SK, et al. Genetic predisposition to lung adenocarcinoma among never-smoking Chinese with different epidermal growth factor receptor mutation status. Lung cancer (Amsterdam, Netherlands). 2017; 114: 79-89.

4. Saldias Penafiel F, Elola Aranguiz JM, Uribe Monasterio J, Morales Soto A, Diaz Patino O. [Risk factors for the development of lung cancer in a cohort of adult smokers]. Revista medica de Chile. 2016; 144: 1382-90.

5. Cruz T, Lopez-Giraldo A, Noell G, Guirao A, Casas-Recasens S, Garcia T, et al. Smoking Impairs the Immunomodulatory Capacity of Lung-Resident Mesenchymal Stem Cells in Chronic Obstructive Pulmonary Disease. American journal of respiratory cell and molecular biology. 2019; 61: 575-83.

6. Nita M, Grzybowski A. Smoking and Eye Pathologies. A Systemic Review. Part II. Retina Diseases, Uveitis, Optic Neuropathies, Thyroid-Associated Orbitopathy. Current pharmaceutical design. 2017; 23: 639-54.

7. Li Y, Xiao X, Ji X, Liu B, Amos CI. RNA-seq analysis of lung adenocarcinomas reveals different gene expression profiles between smoking and nonsmoking patients. Tumour biology : the journal of the International Society for Oncodevelopmental Biology and Medicine. 2015; 36: 8993-9003.

8. Yang $\mathrm{X}$, Chen $\mathrm{R}, \mathrm{Wu} \mathrm{C}$, Zhao W, Ji M. Mutational analysis on gastric, duodenal, bone, and mediastinal lymph node metastases and blood from a case of primary lung adenocarcinoma. OncoTargets and therapy. 2018; 11: 4029-34

9. Niu FY, Zhou Q, Yang JJ, Zhong WZ, Chen ZH, Deng W, et al. Distribution and prognosis of uncommon metastases from non-small cell lung cancer. BMC cancer. 2016; 16: 149

10. Masaoutis C, Mihailidou C, Tsourouflis G, Theocharis S. Exosomes in lung cancer diagnosis and treatment. From the translating research into future clinical practice. Biochimie. 2018; 151: 27-36.

11. Abah U, Casali G, Batchelor TJP, Internullo E, Krishnadas R, Joshi N, et al. Pathological lymph node involvement is not a predictor of adverse outcomes in patients undergoing thoracoscopic lobectomy for lung cancerdagger. European journal of cardio-thoracic surgery : official journal of the European Association for Cardio-thoracic Surgery. 2018; 53: 342-7.

12. Namad T, Wang J, Tilton A, Abdel Karim N. Bilateral choroidal metastasis from non-small cell lung cancer. Case reports in oncological medicine. 2014; 2014: 858265 .

13. Hiley CT, Le Quesne J, Santis G, Sharpe R, de Castro DG, Middleton G, et al. Challenges in molecular testing in non-small-cell lung cancer patients with advanced disease. Lancet (London, England). 2016; 388: 1002-11.

14. Tarro G, Perna A, Esposito C. Early diagnosis of lung cancer by detection of tumor liberated protein. Journal of cellular physiology. 2005; 203: 1-5.

15. Radziszewska A, Karczmarek-Borowska B, Gradalska-Lampart M, Filip AA. [Epidemiology, prevention and risk morbidity factors for lung cancer]. Polski merkuriusz lekarski : organ Polskiego Towarzystwa Lekarskiego. 2015; 38: 113-8.

16. Gajra A, Akbar SA, Din NU. Management of Lung Cancer in the Elderly. Clinics in geriatric medicine. 2016; 32: 81-95

17. Yao LK, Liu GN, Huang SM, Li WT, Li Y. [Relationship between expression of HDAC2, IL-8, TNF-alpha in lung adenocarcinoma tissues and smoking]. Zhonghua yi xue za zhi. 2016; 96: 1410-3.

18. Iwasawa T, Takemura T, Ogura T. Smoking-related lung abnormalities on computed tomography images: comparison with pathological findings. Japanese journal of radiology. 2018; 36: 165-80. 
19. Washko GR, Hunninghake GM, Fernandez IE, Nishino M, Okajima $\mathrm{Y}$, Yamashiro T, et al. Lung volumes and emphysema in smokers with interstitial lung abnormalities. The New England journal of medicine. 2011; 364: 897-906.

20. Craig PJ, Wells AU, Doffman S, Rassl D, Colby TV, Hansell DM, et al. Desquamative interstitial pneumonia, respiratory bronchiolitis and their relationship to smoking. Histopathology. 2004; 45: 275-82.

21. Bak SH, Lee HY. Overlaps and uncertainties of smoking-related idiopathic interstitial pneumonias. International journal of chronic obstructive pulmonary disease. 2017; 12 : 3221-9.

22. Jin GY, Lynch D, Chawla A, Garg K, Tammemagi MC, Sahin H, et al. Interstitial lung abnormalities in a CT lung cancer screening population: prevalence and progression rate. Radiology. 2013; 268: 563-71.

23. Araki T, Putman RK, Hatabu H, Gao W, Dupuis J, Latourelle JC, et al. Development and Progression of Interstitial Lung Abnormalities in the Framingham Heart Study. American journal of respiratory and critical care medicine. 2016; 194: 1514-22.

24. Wu MF, Jian ZH, Huang JY, Jan CF, Nfor ON, Jhang KM, et al. Post-inhaled corticosteroid pulmonary tuberculosis and pneumonia increases lung cancer in patients with COPD. BMC cancer. 2016; 16: 778.

25. Piper ME, McCarthy DE, Baker TB. Assessing tobacco dependence: a guide to measure evaluation and selection. Nicotine \& tobacco research : official journal of the Society for Research on Nicotine and Tobacco. 2006; 8: 339-51.

26. Calejo I, Moreira N, Araujo AM, Carvalho M, Bastos Mde L, de Pinho PG. Optimisation and validation of a HS-SPME-GC-IT/MS method for analysis of carbonyl volatile compounds as biomarkers in human urine: Application in a pilot study to discriminate individuals with smoking habits. Talanta. 2016; 148: 486-93.

27. Gao G, Deng L. [Association between EGFR, ALK and KRAS Gene Status and Synchronous Distant Organ Metastasis in Non-small Cell Lung Cancer]. Zhongguo fei ai za zhi = Chinese journal of lung cancer. 2018; 21: 536-42.

28. Guo $\mathrm{Y}$, Wang $\mathrm{X}$, Xiao J, Xu Y, Cai $\mathrm{Y}$, Sun $\mathrm{C}$, et al. Lung squamous cell carcinoma with solitary ocular metastasis and its successful treatment with thoracic surgery and chemotherapy: an interesting and rare case report. BMC cancer. 2018; 18: 1004 .

29. Hussain S. Nanomedicine for Treatment of Lung Cancer. Advances in experimental medicine and biology. 2016; 890: 137-47

30. Luo J, Yang K, Wen YG. Nested polymerase chain reaction technique for the detection of Gpc3 and Afp mRNA in liver cancer micrometastases. Genetics and molecular research : GMR. 2017; 16.

31. Duffy MJ, Lamerz R, Haglund C, Nicolini A, Kalousova M, Holubec L, et al. Tumor markers in colorectal cancer, gastric cancer and gastrointestinal stromal cancers: European group on tumor markers 2014 guidelines update. International journal of cancer. 2014; 134: 2513-22.

32. Wang $\mathrm{W}, \mathrm{Xu} X$, Tian B, Wang $\mathrm{Y}, \mathrm{Du} \mathrm{L}$, Sun $\mathrm{T}$, et al. The diagnostic value of serum tumor markers CEA, CA19-9, CA125, CA15-3, and TPS in metastatic breast cancer. Clinica chimica acta; international journal of clinical chemistry. 2017; 470: 51-5.

33. Jiang $\mathrm{ZF}$, Wang $\mathrm{M}, \mathrm{Xu}_{\mathrm{U}} \mathrm{JL}$. Thymidine kinase 1 combined with CEA CYFRA21-1 and NSE improved its diagnostic value for lung cancer. Life sciences. 2018; 194: 1-6.

34. Pakdel A, Malekzadeh M, Naghibalhossaini F. The association between preoperative serum CEA concentrations and synchronous liver metastasis in colorectal cancer patients. Cancer biomarkers : section A of Disease markers. 2016; 16: 245-52.

35. Li Y, Tang Z, Qi L, Chen Z, Li D, Zeng M, et al. [Analysis of influential factors for prostate biopsy and establishment of logistic regression model for prostate cancer]. Zhong nan da xue xue bao Yi xue ban = Journal of Central South University Medical sciences. 2015; 40: 651-6.

36. Lyu ZY, Li N, Wang G, Su K, Li F, Guo LW, et al. [Association between total cholesterol and risk of lung cancer incidence in men: a prospective cohort study]. Zhonghua liu xing bing xue za $\mathrm{zhi}=$ Zhonghua liuxingbingxue zazhi. 2018; 39: 604-8.

37. Wu L, Hu B, Zhao B, Liu Y, Yang Y, Zhang L, et al. Circulating microRNA-422a is associated with lymphatic metastasis in lung cancer. Oncotarget. 2017; 8: 42173-88.

38. Chu Y, Lai YH, Lee MC, Yeh YJ, Wu YK, Tsao W, et al. Calsyntenin-1, clusterin and neutrophil gelatinase-associated lipocalin are candidate serological biomarkers for lung adenocarcinoma. Oncotarget. 2017; 8: 107964-76.

39. Brody R, Zhang Y, Ballas M, Siddiqui MK, Gupta P, Barker C, et al. PD-L1 expression in advanced NSCLC: Insights into risk stratification and treatment selection from a systematic literature review. Lung cancer (Amsterdam, Netherlands). 2017; 112: 200-15

40. Wu S, Zhao X, Wu S, Du R, Zhu Q, Fang H, et al. Overexpression of B7-H3 correlates with aggressive clinicopathological characteristics in non-small cell lung cancer. Oncotarget. 2016; 7: 81750-6.

41. Chen Y, Peng W, Huang Y, Chen J, Su G, Jiang C, et al. [Significance of serum neuron-specific enolase before treatment in predicting brain metastases and prognosis of advanced non-small cell lung cancer]. Zhonghua zhong liu za zhi [Chinese journal of oncology]. 2015; 37: 508-11.

42. Jain L, Vargo CA, Danesi R, Sissung TM, Price DK, Venzon D, et al. The role of vascular endothelial growth factor SNPs as predictive and prognostic markers for major solid tumors. Molecular cancer therapeutics. 2009; 8: 2496-508.

43. Oshiro $Y$, Takada $Y$, Enomoto T, Fukao K, Ishikawa S, Iijima T. A resected case of metachronous liver metastasis from lung cancer producing alpha-fetoprotein (AFP) and protein induced by vitamin $\mathrm{K}$ absence or antagonist II (PIVKA-II). Hepato-gastroenterology. 2004; 51: 1144-7.

44. Niklinski J, Furman M, Laudanski J, Kozlowski M. Evaluation of squamous cell carcinoma antigen (SCC-Ag) in the diagnosis and follow-up of patients with non-small cell lung carcinoma. Neoplasma. 1992; 39: 279-82.

45. Hirashima T, Komiya T, Nitta T, Takada Y, Kobayashi M, Masuda N, et al. Prognostic significance of telomeric repeat length alterations in pathological stage I-IIIA non-small cell lung cancer. Anticancer research. 2000; 20: 2181-7.

46. Pollan M, Varela G, Torres A, de la Torre M, Ludena MD, Ortega MD, et al. Clinical value of p53, c-erbB-2, CEA and CA125 regarding relapse, metastasis and death in resectable non-small cell lung cancer. International journal of cancer. 2003; 107: 781-90.

47. Zhou Y, Yu QF, Peng AF, Tong WL, Liu JM, Liu ZL. The risk factors of bone metastases in patients with lung cancer. Scientific Reports. 2017; 7: 8970.

48. Cedres S, Nunez I, Longo M, Martinez P, Checa E, Torrejon D, et al. Serum tumor markers CEA, CYFRA21-1, and CA-125 are associated with worse prognosis in advanced non-small-cell lung cancer (NSCLC). Clinical lung cancer. 2011; 12: 172-9.

49. Zhang L, Liu D, Li L, Pu D, Zhou P, Jing Y, et al. The important role of circulating CYFRA21-1 in metastasis diagnosis and prognostic value compared with carcinoembryonic antigen and neuron-specific enolase in lung cancer patients. BMC cancer. 2017; 17: 96.

50. Chen F, Yan CE, Li J, Han XH, Wang H, Qi J. Diagnostic value of CYFRA 21-1 and CEA for predicting lymph node metastasis in operable lung cancer. International journal of clinical and experimental medicine. 2015; 8: 9820-4.

51. Lee DS, Kim YS, Jung SL, Lee KY, Kang JH, Park S, et al. The relevance of serum carcinoembryonic antigen as an indicator of brain metastasis detection in advanced non-small cell lung cancer. Tumour biology : the journal of the International Society for Oncodevelopmental Biology and Medicine. 2012; 33: 1065-73.

52. Morita S, Suda T, Oda C, Kobayashi M, Hoshi T, Kanefuji T, et al. The Value of (18)F-FDG PET in the Diagnosis of Intertrabecular Vertebral Metastasis in a Small Cell Lung Cancer Patient with a High Serum CEA Level. Internal medicine (Tokyo, Japan). 2019; 58: 415-8.

53. Shetty D, Loh H, Bui C, Mansberg R, Stevanovic A. Elevated 68Ga Prostate-Specific Membrane Antigen Activity in Metastatic Non-Small Cell Lung Cancer. Clinical nuclear medicine. 2016; 41: 414-6. 